\title{
Arsenic controversy needs conclusion
}

The potential threat of arsenic poisoning in Nepal lacks solid empirical evidence

COMMENTARY Himalayan Journal of Sciences 1(1): 10, 2003Download in PDF format

\author{
Rajendra Uprety
}

Although there are several events of arsenic poisoning in Bangladesh and West Bangel, it has never existed in Nepal as a public health problem. Arguments on the basis of location of Terai belt in the same regional geo-chemical condition are non-logical and under controversy. The bad news is that the experts discussed with contradictory figures and nonconvincing analysis. Serious scientific discussions are required to find out the status and threat of arsenic poisoning in Nepal.

Although many more pollution-neutralizing modules have been implemented on the global interest, both the developed and developing countries cannot get rid of the environmental difficulties. At present, environmental hazards entirely cover the whole world posing a strong stress over the living heads of the planet.

Most of the pollution causing agents, spread on globally, has some sort of similarities and a few of them are continental or regional in nature. Arsenic pollution in water in Bangladesh and West Bangel of India could be a typical example. In Bangladesh, over seventy two million people throughout the country have the serious problem of 'Arsenicosis' that resulted from arsenic contamination in water and other feeding sources with arsenic residue.

Environmental Protection Agency (EPA) has already suggested for lowering the value of maximum tolerable limit of arsenic content in water from 0.05 to $0.005 \mathrm{mg} / \mathrm{l}$. Bangladesh, India and Nepal have adapted the value $0.05 \mathrm{mg} / \mathrm{l}$ whereas WHO guideline indicates that the value for safe drinking water must not exceed $0.01 \mathrm{mg} / \mathrm{l}$.

West Bangel has the same plight as of Bangladesh. It is predicted that Nepalese water resources may contains the hazardous substance due to the similar regional geo-chemical condition in Terai belt but the need is it must be identified weather the symptoms be a topic of national interest in the present public health scenario.

Several weeks ago Nepal Chemical Society organized a talk program concerning arsenic pollution and its health impact in Nepal, a challenging topic of hot discussion. Experts from Royal Nepal Academy of Sciences and Technology (RONAST), Department of Irrigation HMG/N, Environment and Public Health Organization (ENPHO) and Ministry of Science and Technology (MOST) opined with their experimental evidences and results to the floor.

At the beginning, the participants have shown a deep interest to the arsenic poisoning in their own home land because they, however not in detail, have listen to some extent about the people suffering arsenic poisoning terribly in Bangladesh and West Bangel of India.

During the presentation, the floor ready to listen the hazardous effect of the arsenic poisoning or its potential threat in the days to come turned its face tired. The contradictory and different nature of presented figures from the experts led them in confusion. They probably raised a question of doubt in their minds weather the arsenic poisoning issue be the topic of national interest in Nepal, where a paracetamol tablet is at far more distance then their death for the country people to meet.

Though the experts were from the apex organizations, the presentation was very poor. The weak and unfulfilled statements from them clears either they presented the facts without any homework or in hurry or without any responsibility to the concerned topic.

There, at the corner, raised voices on the credibility of the analysis. Their arguments made emphasis on the truth; unless the analysis is carried out in inter-laboratory exercise basis it is very difficult to understand the figure and the facts.

http://www.himjsci.com/ - Powered by Mambo Open Source Generated: 23 January, 2008, 07:24 
On hearing with them I have remembered a statement from an official of the Ministry of Population and Environment when I visited him for preparing a series on environmental bad news. The official explained that they have difficulty in analyzing the various figures on environmental issues obtained from different organization due to the associated credibility on facts and figures.

Arsenic poisoning and its potential threat is dangerous, and it is obvious. Today, People in Bangladesh and West Bangel in India are compelled to live under the strain of perilous arsenic poisoning threat but in Nepal, arsenicosis has never existed as a common symptom of public health problem and its effect can be supposed to be less hazardous.

Whatever the situation is in fact, some of the scientists claim that arsenic poisoning is not a great issue in Nepalese environment where millions of the people lack access to safe drinking water, proper solid waste management and have to face dangerous outbreaks annually.

Public health is the concern of all. Therefore, health sector and related experts need to clear that how arsenic poisoning in Nepalese societies is dangerous compared to typhoid or diarrhoea and any other seasonal epidemics.

The most responsible organization generating a database on arsenic and in coordinating with concerned agencies, National Arsenic Steering Committee (NASC), need to crystal clear the status of arsenic problem in Nepalese ground water through a lot of discussion with the related experts in the days to come.

Rajendra Uprety is at Nepal Chemical Society. E-mail: upretyrajendra@yahoo.com 